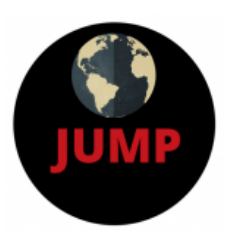

\title{
OJED
}

ISSN: 2574-3465 Print/ ISSN: 2574-3481 Online

Volume 4, Issue 2 (2020), pp. 306-310

(C) Journal of Underrepresented and Minority Progress

http://ojed.org/jump

\section{Feather Boas, Black Hoodies, and John Deere Hats: Discussions of Diversity in K-12 and Higher Education}

Jones, J. R. (Ed.). (2017). Sense Publishers. ISBN: 978-94-6351-215-2

\section{Reviewed By: Tamala Martin, Morgan State University, USA}

Feather Boas,

Black Hoodies, and

John Deere Hats

Discussions of Diversity in K-12

and Higher Education

Joseph R. Jones (Ed.)

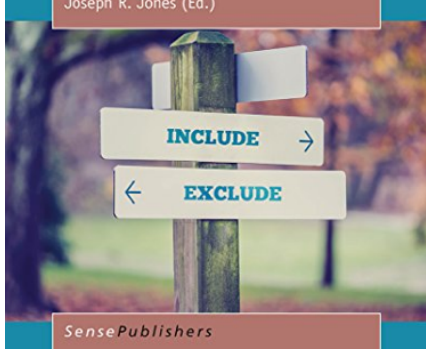

According to the 2010 Census, it is reported that White individuals made up $60.1 \%$ of the United States' population, yielding a population of nearly $40 \%$ of individuals from various other races. Given the diverse nature of the U.S., culturally responsive practices and learning modules are imperative to the health and growth of our nation. Joseph R. Jones' metaphorically titled book Feather Boas, Black Hoodies, and John Deere Hats: Discussions of Diversity in K12 and Higher Education speaks to inequities experienced by those entrenched in the fate of "other-ism" by the lack of inclusivity in such a way that galvanizes the reader to relate and reflect on their own experience enough to want to have a conversation.

Feather Boas, Black Hoodies, and John Deere Hats is comprised of 23 testimonial chapters written through the lens of educators from all walks of life and ethnicities providing a birds-eye view of their experiences navigating in a world of multiculturalism and some cases, their angst for assimilation. The authors' depictions of their experiences were profoundly written. They began to play out in your head as a series of movie shorts whereas you may need to pause in between just to ponder what you just experienced allowing your mind to digest and reflect properly before 
moving on. If I had to pinpoint the main critique, that would be it. You may have to adjust the time frame allocated for the completion of the text.

In Chapter 1, Madison Riley recalls the details of how her first hands-on experiences with unconscious biases infiltrated the small-town homogenous bubble where her abilities and aspirations soared. As her futile attempt to be accepted backfired, she lost her voice. Her burgeoning expertise became minimalized, if not dismissed. It took studying abroad to find it again. Chapter 2 has author Alex Overby grappling with his namesake and the burdens that it created. Whilst his name had evolved through its spelling to dispel the true history of his ancestors, Overby chose to take ownership for the transgressions of his forefathers. Jones skillfully placed Alex Overby's story as a segue to Erin Bentley's story in Chapter 3. As an English teacher, Erin Bentley speaks of the relationships she has with her students stressing the importance of accountabilities and how essential it works both ways. She encouraged her students to embrace their names as opposed to allowing others to assign nicknames because it was easier and convenient. Instituting a "naming ritual" as an icebreaker gave students an increased sense of self-worth. "I do not teach English, I teach students" (p.15). In Chapter 4, Victor Salazar crafted metaphors to increase healthy dialogues between himself and his students. It quickly becomes evident that his approach stems from personal experiences with coping mechanisms incorporated due to the difficulties of his childhood growing up a Hispanic boy grappling with sexuality and poverty. Victor Salazar's story was candidly written as an inspiration for educators to hold students to high regard while valuing their presence.

"To be marginalized is to have a sense that one does not belong and, in doing so, to feel that one is neither a valued member of a community..." (Mowat, 2015, p. 457). Jones's use of Chapters 5 through Chapter 10 addresses the multifaceted depths associated with marginalization in our society. This could be crafted into a well-appointed Venn diagram often used in mathematics to display logical commonalities among different groups. In Chapter 5, a chance encounter with a homeless man forced Thomas Dailey to come face to face with his own implicant biases. Not short of empathy, Mr. Dailey graciously offered a meal to the man acutely aware of the social epithets that stigmatize homeless populations. Thomas Dailey's testimony brings to light the marginalization homeless individuals face even through outreach and other resources. In Chapter 6, Muslim educator Saoussan Maarouf addresses the probable effectiveness of teacher preparation training activities could be the next steps in the battle against Islamophobia without compromising beliefs regarding religion and 
education. Learning about Muslims does not have to be considered religious education. "Some cultures are loud in the way they speak...because invisible hurts" (p. 52).

In Chapter 7, Dr. Carmine Bersh utilizes her testament to invisibility during the recession of 2012 and her unprecedented experiences as an unemployed college professor by demonstrating what it means to regain your voice as a minority. Through the lens of a 20 -year-old male, Chapter 8 depicts the turmoil of growing up gay in the deep south attempting to "pray the gay away" (p. 58). Jones demonstrated how this young man's journey is more evidence of how views of our young people are shaped by their community norms and creating a safe educational environment should move to a more ubiquitous space. In Chapter 9, Chamaree De Silva speaks of growing up educated by an all-female staff instilling the belief that succeeding in math and sciences was not an option but mandated. It wasn't until building her life as a biophysicist in the United States that she had to pummel through levels of microaggressions such as the shocking acknowledgment of her giftedness that her strong upbringing refused to allow her to feel marginalized. Acts of microaggressions are further depicted in Chapter 10 when presumed behaviors of Northerners are not as crass and rude as expected as it graced the college of the Southeast. Actions that are driven by a well-defined "social script and historical narrative" (p. 66). Well-appointed examples are everyday microaggressions that were also highlighted as described: "He's Black but well-spoken. She has a thick Southern accent, but she's very smart. She's a Yankee, but nice" (p. 69) Incorporating best practices through education while embracing the diversity of students was this chapter's catalyst in understanding acceptance and inspirations.

The proceeding chapters highlight teacher effectiveness in a multicultural classroom/setting. In Chapter 11, Justin Maki's take on identifying self-awareness with regards to diversity acknowledgement within pedagogical practices is aptly addressed. In Chapter 12, Vince Youngbauer and Michael Ridgeman delve into the objectification of teachers with noticeable displays of tattoos are subjected to notwithstanding the tendency that female teachers are even less respected or taken seriously. Homophobia is reintroduced in Chapter 13 highlighting the effects of the still prevalent hidden sexuality due to societal views as noted by the existence of heterosexual male to heterosexual male interactions. How educators address these issues and the ensuing bullying is significant to meet the needs of all students. In Chapters14 and 15, Michelle Herring and Jonai Sorrell articulately acknowledge the socio and racial divide ergo advantages 
inherited between themselves and their students and what it's like to inevitably become the minority. In Chapter 16, Tracey Dumas Clark used an outside lens to critique the highly regarded works of Ruby Payne, a renowned educator \& author best known for her strategies on educating the poor and impoverished. She argues that Payne's strategies moved educators to have an indirect correlation between their empathy and expectations of the students thus hindering their intellectual growth.

Chapter 17 addresses the benefits of implementing mandatory coursework to preservice teachers regarding culturally responsive teaching methods as it more specifically relates to international students. Michelle Vaughn aptly suggests that this could include but is not limited to social immersion activities as studying abroad. In Chapter 18, Heather McKeen addresses unconscious biases in the college classroom toward individuals most of whom do not fit the social and academic mold of a typical college student. She discussed activities that encouraged culturally sensitive conversations that would benefit beyond schooling. In Chapter 19, Sherika Derico and Amanda Hawkins seamlessly take the reader into the challenges of increasing diversity in the nursing profession while also highlighting the stigmas geared toward male nurses. "According to the American Association of Colleges of Nursing (2013), diverse males are not adequately represented because of feelings of inadequacy....and fear of gender stereotyping" (p. 150). In Chapter 20, Linda Hensel profoundly highlights the underrepresentation of minorities in STEM-related fields and the need to change the trajectory of those grappling with a defeatist outlook. Carol Raines, in Chapter 21, focused on the impact insensitivity to diversity has on bullying transcending beyond school-aged individuals. "Educators in today's multicultural classrooms need to constantly and consistently be aware of the backgrounds of their students as they plan their lessons" ( $p$. 175); an excerpt from Elizabeth Dore is the trajectory of Chapter 22 and her examinations of methods to making a multicultural education environment successful. In the final chapter, Taylor Rye circled back to the trials of homophobia in the classrooms and preparedness of teachers with this dilemma.

This book touches on all levels of education and could adequately be used as a discussion tool for pre-service educators to a more seasoned professional during coursework and/or professional development. Each of the chapters highlights strategies for incorporating a learning neutral environment. Perspectives from the educator as well the educated allows for constructive conversations that could be had based on those scenarios from K-12 and beyond. Instituting authors from a broad spectrum of the 
educational system were ingenious making content specificity a non-issue. It's narrative adequately aligns with an ever-evolving multicultural society.

\section{REFERENCES}

Mowat, J. (2015). Towards a New Conceptualisation of Marginalisation. European Educational Research Journal, 454-476.

U.S Census Bureau (2010) U.S. Census Bureau Quickfacts.

https://www.census.gov/quickfacts/fact/table/US/PST040219\# PST040219

TAMALA MARTIN, M.Ed is a secondary teacher of mathematics for the Baltimore County School District. Mrs. Martin has also been employed as an adjunct professor at various colleges and universities. Concurrently, she is a part-time instructor of mathematics at Loyola University of Maryland. Her major research interest lies in the area of self-efficacy for minority women in STEM related professions. Email: tamar16@morgan.edu. 